\title{
Percepção dos estudantes de medicina sobre eutanásia, ortotanásia e distanásia
}

\author{
Medical students' perception on euthanasia, orthothanasia and dysthanasia \\ La percepción de los estudiantes de medicina sobre la eutanasia, la ortotanasia y la distanasia
}

Recebido: 05/10/2021 | Revisado: 13/10/2021 | Aceito: 19/10/2021 | Publicado: 21/10/2021

\author{
Bruna Maria Barros de Jesus \\ ORCID: https://orcid.org/0000-0003-1911-7674 \\ Universidade Tiradentes, Brasil \\ E-mail: brubarross31@gmail.com \\ Mylla Crislley Trindade Carvalho \\ ORCID: https://orcid.org/0000-0002-6147-7836 \\ Universidade Tiradentes, Brasil \\ E-mail: myllatcarvalho21@gmail.com \\ Déborah Mônica Machado Pimentel \\ ORCID: https://orcid.org/0000-0003-2102-7125 \\ Universidade Tiradentes, Brasil \\ E-mail: deborahpimentel@icloud.com \\ Roberta Machado Pimentel Rebello de Mattos \\ ORCID: https://orcid.org/0000-0002-7275-2522 \\ Universidade Tiradentes, Brasil \\ E-mail: dra.robertapimentel@ hotmail.com
}

\begin{abstract}
Resumo
Objetivos: Avaliar o nível de conhecimento sobre eutanásia, ortotanásia e distanásia entre estudantes de medicina das universidades de Aracaju; analisar se o conhecimento sobre eutanásia, distanásia e ortotanásia foi aprimorado, com o passar dos anos, nos cursos de medicina e averiguar se os estudantes de medicina concordam/discordam com as práticas da eutanásia, ortotanásia e distanásia. Metodologia: Estudo exploratório, descritivo, transversal e quantitativo; realizado através de questionário aplicado nos acadêmicos de Medicina de duas universidades em Aracaju. Dados analisados com estatísticas descritivas e nível de significância fixado em $\mathrm{p}<0,05$. Resultados: Participaram 222 estudantes de medicina (51\% da universidade pública e $49 \%$ da particular). Destes, $19 \%$ não sabem definir ortotanásia, $7 \%$, eutanásia e $17 \%$, distanásia. Observou-se que do $10^{\circ}$ ao $12^{\circ}$ período, apenas $15 \%$ sabiam definir eutanásia, $15 \%$, distanásia e $16 \%$, ortotanásia. Sobre aprovação, $54 \%$ aprovam a eutanásia, $74 \%$, a ortotanásia e $43 \%$ aprovam a distanásia sem saber o seu conceito. Considerações finais: A graduação médica é incipiente nesta temática, pois, errar definição é indicativo básico de desestruturação, causando despreparo cotidiano. Concordar/discordar com as práticas é influenciado pelo conhecimento, assim, quase metade dos estudantes aprovaram a distanásia sem saber seu significado, aumentando probabilidade de futuro erro médico, imperícia ou outras infrações graves. Existe diminuição nos acertos dos estudantes que estão na iminência da formação, demonstrando que não há intervenções para aprimoramento do conhecimento ao longo da faculdade. Incluir disciplinas bioéticas com conhecimento sobre eutanásia, distanásia, ortotanásia e processo de morte, seguida por oportunidades de atuação, indicam bom começo nas intervenções necessárias.
\end{abstract}

Palavras-chave: Atitude frente a morte; Conhecimento; Cuidados paliativos; Estudantes de medicina; Eutanásia.

\begin{abstract}
Objectives: To assess the knowledge level on euthanasia, orthothanasia and dysthanasia among medical students at universities in Aracaju; to analyze whether knowledge on euthanasia, dysthanasia and orthothanasia has been improved over the years in medical courses and to verify whether medical students agree/disagree with the practices of euthanasia, orthothanasia and dysthanasia. Methodology: Exploratory, descriptive, cross-sectional and quantitative study; produced through a questionnaire applied to medical students at two universities in Aracaju. Data analyzed with descriptive statistics and significance level set at $\mathrm{p}<0.05$. Results: 222 medical students participated (51\% from public and $49 \%$ from private universities). Of these, $19 \%$ did not know how to define orthothanasia, $7 \%$ euthanasia and $17 \%$ dysthanasia. It was observed that from the 10th to the 12th period $15 \%$ knew how to define euthanasia, $15 \%$ dysthanasia and $16 \%$ orthothanasia. On approval, 54\% approved of euthanasia, $74 \%$ of orthothanasia and $43 \%$ approved of dysthanasia without knowing its concept. Final considerations: Medical graduation is incipient in this issue, as a wrong definition is a basic indication of destructuring, causing daily unpreparedness. Agreeing/disagreeing with practices is influenced by knowledge, thus, almost half of the students approved dysthanasia without knowing its meaning, increasing the probability of future medical error, malpractice or other serious infractions. There is a decrease in correct answers for students who are about to graduate, showing that there are no interventions to improve
\end{abstract}


knowledge throughout college. Including bioethical subjects about euthanasia, dysthanasia, orthothanasia and death process, and acting opportunities, indicate a good start in the interventions required.

Keywords: Attitude towards death; Euthanasia; Knowledge; Medical students; Palliative care.

\begin{abstract}
Resumen
Objetivos: Evaluar el nivel de conocimiento sobre eutanasia, ortotanasia y distanasia entre los estudiantes de medicina de las universidades de Aracaju; analizar si el conocimiento sobre este tema fue incrementado a lo largo de los años, en los cursos de medicina y averiguar si los estudiantes de medicina están de acuerdo/discuerdan con estas práticas. Metodología: Estudio exploratorio, descriptivo, transversal y cuantitativo; aplicando un cuestionario a estudiantes de medicina de dos universidades de Aracaju. Análisis con estadísticas descriptivas y nivel de significación fijado en $\mathrm{p}$ $<0,05$. Resultados: Participaron 222 estudiantes de medicina (51\% de la universidad pública y $49 \%$ de la universidad privada). El 19\% no supo definir la ortotanasia, el 7\% la eutanasia y el 17\% la distanasia. Del décimo al duodécimo periodo, el 15\% sabía definir la eutanasia, el 15\% la distanasia y el 16\% la ortotanasia. El 54\% aprueba la eutanasia, el $74 \%$ la ortotanasia y el $43 \%$ la distanasia, sin conocer el concepto. Consideraciones finales: la graduación médica es incipiente, ya que errar en la definición es indicativo de desestructuración. El acuerdo/desacuerdo está influenciado por el conocimiento, por lo que casi la mitad aprobó la distanasia sin conocer su significado, lo que aumenta la probabilidad de error médico y otras infracciones. Hay una disminución de las respuestas correctas de los académicos cuando están a punto de graduarse, lo que demuestra un fracaso en la mejora de los conocimientos durante la universidad. Incluir temas de bioética y oportunidades de acción son buenas intervenciones iniciales.
\end{abstract}

Palabras clave: Actitud hacia la muerte; Conocimiento; Cuidados paliativos; Estudiantes de medicina; Eutanasia.

\title{
1. Introdução
}

Entender a morte, o morrer, o significado de uma morte digna e a linha tênue que separa estas questões da terapêutica médica, como o uso de medicamentos e procedimentos técnicos, é de suma importância para os estudantes de medicina e os próprios médicos que convivem com isso diariamente. A construção do entendimento acerca da morte está condicionada principalmente a dois fatores sociais: cultura e religião (Couceiro et al., 2019; Lysakowski \& Menin, 2019; Martins et al., 2019). Nota-se a falta de abordagens deste assunto durante a graduação e essa falta de intimidade com o tema é, na maioria das vezes, a principal etiologia da sensação de impotência diante da limitação de cura, relatada por vários profissionais da saúde (Ferreira et al., 2018).

Nesse cenário, é necessário captar a percepção dos alunos e seus sentimentos para lidar com esse tipo de situação. Há controvérsias acerca da temática da ética no manejo do fim da vida e a aplicabilidade clínica, pois, apesar da morte ter significados simbólicos e ser inerente ao ser humano, o desconhecimento do acadêmico incita a insegurança e ansiedade pautadas nas dúvidas que poderão surgir e na crença de que a morte - caso não seja evitada pelo médico - é sinônimo de falha nas escolhas terapêuticas realizadas (Correia et al., 2020).

O tema morte sempre foi visto como algo indesejado. Mesmo sabendo-se que faz parte do ciclo natural do ser humano, assume um lugar camuflado, como se fosse algo para proteção da vida e escondido nos hospitais em total silêncio. Dessa forma, verifica-se a morte como algo externo ao meio social, de motivo extrínseco, e a medicina como uma forma de "luta" contra ela (Duarte et al., 2015). Sendo assim, estudos que englobam a temática da morte e seus quesitos associados têm estimulado uma maior reflexão por parte dos estudantes da área da saúde no geral (Couceiro et al., 2019; Trevisano et al., 2019).

Em um estudo realizado por Santos et al. (2020), observou-se que alguns estudantes da área da saúde associaram a morte à um fim de ciclo biológico, em que o organismo perde sua funcionalidade; enquanto outros relacionaram às questões religiosas. Morrer não é algo exclusivo de uma condição clínica e abrange aspectos éticos, sociais, culturais e religiosos do paciente. No Brasil, o direito humano de morrer dignamente está implícito na Constituição (Brasil, 1988). Assim, a decisão de prolongar ou interromper a vida é polêmica e por isso envolve princípios éticos e jurídicos. Dessa forma, a eutanásia, a distanásia e ortotanásia ainda são temas bastante discutidos, por terem seus limites confundidos. 
A palavra eutanásia é de origem grega, com significado de "boa morte" e refere-se ao esforço de minimizar dor e sofrimento prolongado com o encurtamento da vida (Lins et al., 2018). No caso da distanásia, ocorrem aplicação de situações que prolongam o processo de morte, ou seja, uma obstinação terapêutica sem perspectivas de melhora. Sendo assim, uma nova fase deve ser orientada e instituída ao indivíduo acometido por alguma enfermidade que não tenha recuperação: o cuidado sem ter a cura como objetivo final, que potencialmente acarretará angústia, sofrimento e dor tanto para o paciente, quanto para sua família (Cardin \& Nery, 2021; Felix et al., 2013). Já a ortotanásia é o processo natural de morte, após interromper tratamentos fúteis apresentando-se como uma arte do bem morrer e garantindo a dignidade, ou seja, permite que a morte seja enfrentada com mais naturalidade e a vida seja mantida apenas até a fase em que o enfermo não está sendo maleficiado (Almeida \& Melo, 2018; Cano et al., 2020).

Cuidados paliativos (CP) é uma abordagem ou tratamento que melhora a qualidade de vida de pacientes e familiares diante de doenças que ameacem a continuidade da vida: a ortotanásia (D’Alessandro et al., 2020; World Health Organizacion, 2002). Isto é realizado através da prevenção e alívio das situações que foram visualizadas ao longo do caso e com tratamento específico para aquele paciente (Dubón-Peniche \& Bustamente-Leija, 2020). Todavia, identificar pacientes que completam os pré-requisitos para realização de $\mathrm{CP}$ é bastante desafiador na área da saúde, devido justamente às lacunas existentes nas grades universitárias (Lopes et al., 2019). Para que os cuidados paliativos aconteçam, existe a necessidade de uma equipe multidisciplinar, que ficará responsável por englobar os aspectos biopsicossociais do paciente e ajudá-lo, assim como sua família, a se moldar às mudanças em suas vidas e a lidar com uma nova condição de sobrevivência ou até com uma possível morte (Cruz et al., 2021). É mister ressaltar que, dentro dos protocolos para liberação de sua prática, destaca-se o Testamento Vital e o Consentimento Informado (instrumentos que o próprio paciente pode solicitar, enquanto estiver apto civilmente) (Felix et al., 2013).

Estudantes de medicina e médicos devem ter conhecimentos básicos sobre a ética da profissão e os cuidados paliativos. Conforme Aragão (2018), alunos do nono semestre de Medicina em uma universidade em Aracaju foram questionados sobre conceitos da área prática de $\mathrm{CP}$ e apenas 51,1\% responderam corretamente. Após ministração de uma palestra acerca da temática, a mesma questão foi abordada e este índice de acerto chegou a 97,9\%, ou seja, a disseminação das informações através de aulas ou qualquer outro meio que atinja esse público é de extrema relevância no crescimento de uma reflexão cada vez mais adequada aos fatores necessários.

Diante do exposto, pode-se afirmar que há extrema necessidade em debater as insufiências das universidades com relação tanto à percepção dos acadêmicos de medicina sobre eutanásia, distanásia e ortotanásia, quanto ao enfrentamento da morte. Assim, é possivel instalar melhorias concretas e embasadas no cotidiano e nas especificidades de cada método de aprendizagem adotado na instituição. Devido a isto, objetivou-se com este estudo avaliar o nível de conhecimento sobre eutanásia, ortotanásia e distanásia entre estudantes dos cursos de medicina das universidades da cidade de Aracaju; analisar se o conhecimento sobre eutanásia, distanásia e ortotanásia foi aprimorado, com o passar dos anos, nos cursos de medicina e averiguar se os estudantes de medicina concordam ou não com as práticas da eutanásia, ortotanásia e distanásia.

\section{Metodologia}

O projeto foi submetido e aprovado no Comitê de Ética em Pesquisa da Universidade Tiradentes (CAAE: 12200119.8.0000.5371) e realizado um estudo exploratório, descritivo, transversal e de abordagem quantitativa na Universidade Tiradentes e na Universidade Federal de Sergipe. Foram incluídos acadêmicos devidamente matriculado nos cursos de Medicina de Aracaju e a amostra foi obtida utilizando uma hipótese de que no mínimo 10\% dos estudantes, tinham um bom nível de conhecimento sobre os conceitos de eutanásia, distanásia e ortotanásia. Sendo assim, para a coleta de um 
universo de 1200 acadêmicos de medicina das universidades pública e privada de Aracaju, buscou-se uma amostra de 220 participantes, com erro amostral de 5\% e nível de confiança de 95\% (SurveyMonkey Audience, 2019).

A pesquisa dividiu-se em duas etapas: a primeira consistiu-se de um questionário que identificou as características sociodemográficas dos participantes, seus períodos do curso de medicina e sua instituição; a segunda etapa foi baseada em um instrumento adaptado de Moraes e Kairalla (2010); Silva et al. (2015) e Leite et al. (2018), onde foram selecionadas algumas questões pelos autores para uma auto avaliação geral sobre eutanásia, distanásia e ortotanásia. Na análise dos resultados, é importante esclarecer que responder as questões era opcional, ou seja, o aluno poderia se recusar/ não marcar nenhuma alternativa.

Conforme Resolução CNS 466/12, os entrevistados assinaram um Termo de Consentimento Livre e Esclarecido, garantindo o anonimato e a possibilidade de retirar seu consentimento a qualquer momento, sem quaisquer tipos de prejuízos.

Para finalizar, o tratamento dos dados foi realizado utilizando o software SPSS 22.0 e a análise através de estatísticas descritivas (desvio padrão, média, valor mínimo, valor máximo, percentagens), com nível de significância fixado em $\mathrm{p}<0,05$ para todos os testes.

\section{Resultados}

Participaram do estudo 222 estudantes de medicina, sendo $51 \%$ da universidade pública e $49 \%$ da particular. Destes, $51 \%$ foram do sexo feminino e 49\%, masculino, com predominância da faixa etária entre 20 e 30 anos (86\%). Quando observou-se o período dos entrevistados, $42 \%$ estavam no sétimo ao nono período, seguidos por 33\% do quarto ao sexto período, $15 \%$ do décimo ao décimo segundo e apenas $10 \%$ do primeiro ao terceiro. Ademais, no quesito religião, $48 \%$ representaram a maioria e declararam-se católicos, com apenas $6 \%$ de espíritas, em último lugar.

Ao serem interrogados se estavam preparados para lidar com a morte de um paciente, 62\% dos estudantes responderam que não, mas não associaram a morte com derrota, perda e/ou frustração; apenas 32\% referiram encarar esse processo com naturalidade e $6 \%$ afirmaram que não sabem lidar com o processo de morrer e a morte e associam à derrota, perda e/ou frustração. Ainda neste cenário, foi possível perceber que $71 \%$ dos estudantes da universidade pública consideramse preparados para lidar com a morte e encaram-na com naturalidade; já na instituição privada, esta porcentagem é de apenas $29 \%$. Notou-se ainda que a maioria que se sente preparado e enxerga essa etapa como um processo natural é do $7^{\circ}$ ao $9^{\circ}$ período da formação médica.

Considerando o questionário aplicado, a maior parte dos acadêmicos respondeu corretamente as definições de ortotanásia, eutanásia e distanásia (Tabela 1).

Tabela 1 - Conhecimento sobre eutanásia, ortotanásia e distanásia.

\begin{tabular}{lllll}
\hline & \multicolumn{2}{c}{ Resposta Correta } & \multicolumn{2}{c}{ Resposta Incorreta } \\
& $\mathbf{N}$ & $\mathbf{\%}$ & $\mathbf{N}$ & $\mathbf{\%}$ \\
\hline O que é ortotanásia & 179 & $81 \%$ & 43 & $19 \%$ \\
O que é eutanásia & 206 & $93 \%$ & 16 & $7 \%$ \\
O que é distanásia & 185 & $83 \%$ & 37 & $17 \%$ \\
\hline
\end{tabular}

Fonte: Autores.

Quando analisamos o perfil dos estudantes em relação ao conhecimento do tema abordado, constatamos que, sobre a ortotanásia, $58 \%$ dos acadêmicos da universidade particular e $42 \%$ da pública, responderam incorretamente. O período em que os alunos mais responderam foi o intervalo entre o sétimo e nono período e, em geral, responderam incorretamente (Tabela 2). 
Tabela 2 - Conhecimento sobre ortotanásia por perfil do estudante.

\begin{tabular}{ccccc}
\hline & \multicolumn{2}{c}{ Resposta Correta } & \multicolumn{2}{c}{ Resposta Incorreta } \\
& $\mathbf{N}$ & $\mathbf{\%}$ & $\mathbf{N}$ & $\mathbf{\%}$ \\
\hline $\begin{array}{c}\text { Instituição } \\
\text { Universidade }\end{array}$ & & & & \\
Federal de Sergipe (UFS) & 95 & $53 \%$ & 18 & $42 \%$ \\
Universidade & & & & \\
Tiradentes (UNIT) & 84 & $47 \%$ & 25 & $58 \%$ \\
Período & & & & \\
Do $1^{\circ}$ ao $3^{\circ}$ período & 18 & $10 \%$ & 5 & $12 \%$ \\
Do $4^{\circ}$ ao $6^{\circ}$ período & 59 & $33 \%$ & 14 & $33 \%$ \\
Do $7^{\circ}$ ao $9^{\circ}$ período & 74 & $41 \%$ & 19 & $44 \%$ \\
Do $10^{\circ}$ ao $12^{\circ}$ período & 28 & $16 \%$ & 5 & $12 \%$ \\
\hline
\end{tabular}

Fonte: Autores.

Quando analisado o perfil do entrevistado com relação ao seu conhecimento sobre eutanásia, percebeu-se que o maior número encontra-se na fase final do ciclo básico ou já inserido no internato médico; mas houve uma queda significativa quando se compara ao nível de acerto dos internos entre $10^{\circ}$ e $12^{\circ}$ períodos (Tabela 3).

No que diz respeito a distanásia, períodos iniciais como $4^{\circ}$ ao $6^{\circ}$ se destacaram quando comparados aos estudantes na reta final da graduação (Tabela 4).

Tabela 3 - Conhecimento sobre eutanásia por perfil do estudante.

\begin{tabular}{llllc}
\hline & \multicolumn{2}{c}{ Resposta Correta } & \multicolumn{2}{c}{ Resposta Incorreta } \\
& $\mathbf{N}$ & $\mathbf{\%}$ & $\mathbf{N}$ & $\mathbf{\%}$ \\
\hline Instituição & & & & \\
UFS & 107 & $52 \%$ & 6 & $40 \%$ \\
UNIT & 100 & $48 \%$ & 9 & $60 \%$ \\
Período & & & & $7 \%$ \\
Do $1^{\circ}$ ao $3^{\circ}$ período & 22 & $11 \%$ & 1 & $53 \%$ \\
Do $4^{\circ}$ ao $6^{\circ}$ período & 65 & $31 \%$ & 8 & $33 \%$ \\
Do $7^{\circ}$ ao $9^{\circ}$ período & 88 & $43 \%$ & 5 & $7 \%$ \\
Do $10^{\circ}$ ao $12^{\circ}$ período & 32 & $15 \%$ & 1 & \\
\hline
\end{tabular}

Fonte: Autores.

Tabela 4 - Conhecimento sobre distanásia por perfil do estudante.

\begin{tabular}{lcccc} 
& Resposta Correta & \multicolumn{2}{c}{ Resposta Incorreta } \\
& $\mathbf{N}$ & $\mathbf{\%}$ & $\mathbf{N}$ & $\%$ \\
\hline Instituição & & & & \\
UFS & 94 & $51 \%$ & 17 & $46 \%$ \\
UNIT & 91 & $49 \%$ & 18 & $5 \%$ \\
Período & & & 2 & $46 \%$ \\
Do $1^{\circ}$ ao $3^{\circ}$ período & 21 & $11 \%$ & 17 & $30 \%$ \\
Do $4^{\circ}$ ao $6^{\circ}$ período & 55 & $30 \%$ & 11 & $14 \%$ \\
Do $7^{\circ}$ ao $9^{\circ}$ período & 81 & $44 \%$ & 5 & \\
Do $10^{\circ}$ ao $12^{\circ}$ período & 28 & $15 \%$ & & \\
\hline
\end{tabular}

Fonte: Autores. 
Sobre a ideia de aprovar a prática de eutanásia, 54\% responderam que aprovam; destes, $45 \%$ são da universidade federal e $55 \%$ da particular, cursando principalmente do $4^{\circ}$ ao $6^{\circ}$ período da graduação (38\%). No patamar dos alunos em fase final do curso, do $10^{\circ}$ ao $12^{\circ}$ períodos, apenas $17 \%$ aprovam, contra $28 \%$ que responderam não.

Quando a análise foi acerca da comparação entre as respostas corretas sobre os conceitos e a aprovação da prática, percebeu-se que, de modo geral, os alunos que acertaram as definições de ortotanásia e eutanásia são a favor de suas realizações; no cenário da distanásia, ficou nítido que, ao ser bem esclarecido sobre o tema, a prática é desaprovada (Tabela 5).

Comprovamos ainda que, $86 \%$ dos acadêmicos de medicina sabem corretamente o que é distanásia e não aprovam sua prática; existem $43 \%$ que aprovam a prática da distanásia sem saber o seu conceito; o restante, $14 \%$, acertaram a definição, mas relataram não possuir opinião formada sobre a aplicação (Tabela 5).

Tabela 5 - Alunos que aprovam e desaprovam a prática de ortotanásia, eutanásia e distanásia versus alunos que acertaram e erraram os respectivos conceitos.

\begin{tabular}{lllll}
\hline Variável & Acertou & & Errou & \\
& $\mathbf{N}$ & $\mathbf{\%}$ & $\mathbf{N}$ & $\mathbf{\%}$ \\
\hline Ortotanásia & & & & \\
Aprova & 148 & $83 \%$ & 15 & $35 \%$ \\
Não aprova & 5 & $3 \%$ & 5 & $12 \%$ \\
Sem opinião formada & 25 & $14 \%$ & 23 & $53 \%$ \\
Eutanásia & & & & \\
Aprova & 114 & $55 \%$ & 5 & $33 \%$ \\
Não aprova & 24 & $12 \%$ & 1 & $7 \%$ \\
Sem opinião formada & 68 & $33 \%$ & 9 & $60 \%$ \\
Distanásia & & & & \\
Aprova & - & - & 15 & $43 \%$ \\
Não aprova & 159 & $86 \%$ & 6 & $17 \%$ \\
Sem opinião formada & 26 & $14 \%$ & 14 & $40 \%$ \\
\hline
\end{tabular}

Fonte: Autores.

No caso da ortotanásia, notou-se que $74 \%$ dos entrevistados concordam com sua prática, seguidos por $22 \%$ que não possuem opinião formada sobre o assunto (Tabela 6).

Tabela 6 - "Você aprova a aplicação de ortotanásia?"

\begin{tabular}{lcc}
\hline & $\mathbf{N}$ & $\mathbf{\%}$ \\
\hline Sim & 163 & $74 \%$ \\
Não & 10 & $5 \%$ \\
Sem opinião formada & 48 & $22 \%$ \\
Total & 221 & $100 \%$ \\
\hline
\end{tabular}

Fonte: Autores.

Com relação ao preparo de uma equipe de cuidados paliativos, $99 \%$ dos discentes acertaram ao indicar que o ideal é que esta seja interdisciplinar e siga o princípio de humanização, priorizando bem-estar físico, emocional e espiritual do paciente.

Outrossim, questionaram-se os temas que tais acadêmicos recordavam ter discutido na graduação, as opções foram: testamento vital, ortotanásia, distanásia e eutanásia, cuidados paliativos e obstinação terapêutica. Dessa maneira, observou-se 
que $76 \%$ dos estudantes da instituição particular não discutiram nenhum dos assuntos citados, enquanto na pública, apenas $24 \%$ não tiveram nenhum contato com tais temáticas, pelo que recordam.

No contexto de grades curriculares das faculdades de Medicina, questionamos aos entrevistados o que consideravam em falta na sua formação para lidar melhor com o processo de morrer. À vista disto, $46 \%$ apontaram a necessidade de inclusão de uma matéria/componente curricular que lide com tal temática; 33\% indicaram a necessidade de oportunidades para lidar com os aspectos emocionais, espirituais e sociais do ser humano, bem como o contato com pacientes que não têm nenhuma possibilidade de cura; $14 \%$ perceberam que é mister uma sensibilização por parte dos professores, a fim de fazê-los pensar sobre o assunto; apenas $2 \%$ declararam-se totalmente preparados.

Por fim, aprofundando no perfil dos estudantes que responderam essa questão, é notório que a maioria (75\%) dos que se sentem totalmente preparados são da universidade federal, enquanto que, na universidade particular, esta porcentagem é de apenas $25 \%$; além disso, somente $25 \%$ dos acadêmicos do $10^{\circ}$ ao $12^{\circ}$ períodos responderam sentir-se preparados.

\section{Discussão}

Inicialmente, encontrou-se predomínio do sexo feminino, alinhando-se com o resultado obtido por Orth et al. (2020) após analisar o conhecimento do acadêmico de medicina sobre cuidados paliativos. Somado a isto, verificou-se a concordância com outros estudos anteriores que demonstram o desenvolvimento e crescimento das mulheres nas universidades de Medicina do Brasil. É importante salientar também que o sexo feminino distribui-se cada vez mais por profissões que eram majoritariamente preenchidas pelo sexo oposto, principalmente no setor público, provavelmente pelo fato de que o acesso via concurso público possa reduzir a discriminação (Aguiar et al., 2020; Fiorotti et al., 2010; Lira et al., 2021; Ricoldi et al., 2016).

De acordo com entrevista semiestruturada conduzida no estudo de Azeredo et al. (2011), os acadêmicos relataram sentimento de frustração e incapacidade diante da morte devido falta de preparo na etapa universitária. Ademais, a terminalidade da vida exige contato com várias outras emoções relacionadas à perda e, assim sendo, a autorreflexão sobre isto, expondo o despreparo para lidar com esta situação, possibilita mudanças na visão do aluno para aprimoramento das ações cotidianas (Correia et al., 2020). Dessa maneira, podemos constatar que nossa análise ratifica isto, pois a maioria dos estudantes de ambas as universidades não se sentem preparados para lidar com a morte, o que confirma ainda mais a necessidade de reformulações constantes e atuais que englobem os déficits apontados.

Outro ponto importante é o fato de que na pesquisa realizada, a diferença entre o preparo para lidar com a morte é extremamente significativa quando comparamos faculdade pública e privada. Foi na universidade pública que a maior parte dos acadêmicos indicaram estar preparados para lidar com este processo e ainda enfrentá-la com naturalidade. Ou seja, há correlação com uma maior deficiência acerca deste tema na grade curricular da instituição privada, ratificada na pesquisa de Barroso et al. (2020), pois 56,82\% dos estudantes de medicina de uma insitituição privada de Teresina-Piauí afirmaram não existir uma disciplina que aborde o tema em sua grade curricular. Ainda de acordo com o estudo de Barroso et al. (2020), 97,73\% dos alunos acreditam que o seu curso de Medicina deveria agir ativamente na preparação para enfrentar a situação de morte, através principalmente de disciplinas $(37,21 \%)$, exercícios práticos $(32,56 \%)$, palestras/discussões $(25,58 \%)$ e por último, apoio psicológico (4,65\%).

Pode-se observar também que, em relação ao conhecimento dos estudantes de medicina referente à eutanásia, distanásia e ortotanásia, a maioria afirma corretamente as definições sobre o tema. Nesse cenário, a maior taxa de acerto está entre os estudantes do último ano da graduação e isto estaria associado ao fato de que este grupo de entrevistados já participaram das atividades práticas do internato e portanto exerceram a relação médico-paciente, vivenciando o tema em situações cotidianas. Percebe-se ainda que a prática da distanásia é aprovada por $43 \%$ dos entrevistados que não sabem o seu 
conceito, por conseguinte, estão passíveis de infringir a Ética Médica. Se faz necessário atingir estes estudantes com informações científicas para que possam construir com mais cautela seu senso crítico.

Com relação ao perfil dos acadêmicos que definiram corretamente eutanásia, distanásia e ortotanásia, perceptivelmente há uma limitação maior de conhecimento. Nesse contexto, observou-se que esta restrição não foi corrigida com o passar do tempo, para os acadêmicos do $10^{\circ}$ ao $12^{\circ}$ período. Pois, apesar da faixa entre $7^{\circ}$ e $9^{\circ}$ possuir o maior acerto nos três temas, existe uma queda brusca nos acertos entre os estudantes que estão na iminência da formação universitária. Contudo, ambos estão no internato e a disparidade estaria na quantidade de horas a mais na vivência dos quase egressos, não sendo possível estimar relação com os estágios participados das especialidades médicas nesta fase da graduação, pois há uma aleatoriedade nas escolhas da ordem de execução. Ademais, uma das principais intervenções para diminuir a quantidade de estudantes que não sabem a definição de ortotanásia, distanásia e eutanásia, teria suma importância neste momento: a administração de aulas ou palestras que englobem a temática necessária, pois, já provou-se através de um estudo com coleta de respostas sobre questões da área prática de cuidados paliativos que após a ministração de palestra para os alunos, o nível de conhecimento cresceu em média 50\%, alcançando um nível de quase 100\% de acertos (Aragão, 2018).

Outra análise válida é o fato de que apesar do $7^{\circ}$ ao $9^{\circ}$ período demonstrar ser a faixa que mais possui conhecimento adequado sobre os tópicos, $64 \%$ dos alunos associam a morte com sentimentos de derrota, perda e frustração, e isto prova a visão demonstrada no estudo de Duarte et al. (2015), em que a morte foi caracterizada como momento bastante difícil de lidar, uma situação do cotidiano médico que ainda é tabu e não discutida como deveria, na preparação acadêmica. Dessa maneira, é notório a falta de debates psicossociais que edifiquem a visão tanto psicológica, quanto social destes acadêmicos, já que a morte deve ser tratada verdadeiramente como o processo natural da vida, contudo, sem ultrapassar as fronteiras para a naturalização enrijecida e tecnicista cotidiana.

Os pesquisadores do presente estudo indagaram ao estudante de medicina o que ele considerava em falta na sua formação para lidar melhor com a morte no âmbito da profissional: quase metade apontou a inclusão de disciplinas que lidem com questões relacionadas à Bioética, conhecimento sobre eutanásia, distanásia, ortotanásia e lidar com o processo de morte, seguida por oportunidades para atuar com estes aspectos. Ou seja, opções que já são discutidas há anos em estudos anteriores, indicando o fato desta precariedade de abordagens ser o ponto crucial nos sentimentos de perda, frustração, incapacidade, entre outros, relatados pelos profissionais da saúde que são reflexos de acadêmicos com esta carência teórica (Ferreira et al., 2018).

Os avanços tecnológicos, principalmente na área médica, permitiram o prolongamento da vida e o maior controle do processo da morte. Assim, cabe ao médico tomar a decisão sobre os últimos dias dos pacientes em estado terminal, sempre respeitando não apenas sua autonomia e os princípios éticos e jurídicos sobre o direito de morrer com dignidade (Morais et al., 2016), mas também a "premissa básica da arte médica: primum non nocere (em primeiro lugar, não causar o mal)" (Muñoz, 2004). Saber lidar com o processo de morte do paciente não é tarefa fácil e requer muito senso crítico. Concomitantemente, o paciente que está em fase terminal, tem o direito de exercer sua autonomia ao opinar sobre o seu processo de morte. De acordo com este mesmo princípio autonômico, os profissionais devem explicar todas as informações acerca da enfermidade ao indivíduo, justamente para que as vontades pessoais do enfermo acerca do tratamento instituído sejam respeitadas adequadamente. Este é mais um motivo que afirma a grande necessidade não apenas de manejar, mas também de possuir o conhecimento ideal sobre eutanásia, distanásia, ortotanásia, tanatologia e demais assuntos relacionados à Bioética e Éticamédica, para o bom desempenho profissional (Scottini et al., 2018).

Diante de tudo citado anteriormente, foi possível analisar ainda, através da mesma coleta de dados, como os estudantes expressaram-se acerca da concordância com a prática da eutanásia, distanásia e ortotanásia. Nesse cenário, com um nível de 5\% de significância (estabelecido pelo pesquisador/estatístico), obteve-se um p-valor maior que 0,05 para a prática de eutanásia, portanto, a hipótese nula de que a aprovação da prática de eutanásia e os acertos sobre a sua definição são 
independentes, ou seja, há evidências para afirmarmos que não existe associação entre o conhecimentos dos alunos sobre a definição/visualização da prática de eutanásia com o fato dos mesmos concordarem ou não. Além disso, pelo mesmo motivo, as evidências indicam que, com um nível de significância de 5\%, obteve-se um p-valor menor que 0,05 para as práticas de ortotanásia e distanásia. Portanto, as evidências indicam que existe associação entre o entrevistado saber o conceito e concordar com a prática das mesmas.

As pessoas buscam os médicos com a intenção de alívio ou cura da enfermidade que estão enfrentando. Sendo assim, a legalização da prática de eutanásia alteraria o papel médico em sociedade, concedendo-o o encargo de determinar a vida. Por conseguinte, haveria estremecimento da relação médico-paciente por desestabilizar os laços de confiança e desencorajarem os avanços na busca do melhor acompanhamento humanizado do enfermo (Zurriaráin, 2019). Logo, a análise dos dados demonstrou que apesar de não terem sido os que mais acertaram a definição de eutanásia, os entrevistados do $4^{\circ}$ ao $6^{\circ}$ período foram os que mais aprovaram a aplicação, com destaque ao ensino particular; houve ainda $12 \%$ das respostas corretas que indicaram não aprovar a prática da eutanásia.

A medicina atual visa a cura da doença, rotulando as enfermidades como adversárias constantes, geradoras dos sentimentos negativos, e visualizando os métodos curativos apenas como forma de afastar o paciente da morte (Azeredo et al., 2011; Siqueira Perboni et al., 2018). Isto pode ocasionar a distanásia, uma infração ética grave associada a um tratamento fútil, denominado por Sigmund Freud como furor curandis do médico e que foi duramente criticado pelo fanatismo que pode associar-se às causas desta violação (Barbieri \& Sarti, 2011; Neves, 2020). Posto isto, percebemos com a análise dos resultados obtidos que o fato de saber corretamente o que é distanásia, evita que aprovem sua realização, já que 86\% deste grupo não concordam que seja realizada. Todavia, vale ressaltar que houve uma porcentagem considerável de estudantes que admitiram não ter opinião formada sobre um assunto que traz um problema ético tão maléfico ao paciente; são, em geral, justamente os que erraram o conceito da distanásia. Ou seja, além do contato com a definição teórica em si, se faz necessário também o aprimoramento do contato em algum momento do ensino, com os princípios do código de ética médica na relação médicopaciente.

Desde 2010, a ortotanásia é permitida em território brasileiro, permitindo ao próprio paciente, ou a pedido de familiares em caso de impossibilidade do mesmo, a suspensão dos medicamentos para que possa chegar a óbito de forma natural, já que a medicina curativa se esgotou para tal enfermo (Santos et al., 2013). Além de que, esta ação está explicada na resolução 1.805/2006 do Conselho Federal de Medicina, onde explicita-se que "na fase terminal de enfermidades graves e incuráveis é permitido ao médico limitar ou suspender procedimentos e tratamentos que prolonguem a vida do doente, garantindo-lhe os cuidados necessários para aliviar os sintomas que levam ao sofrimento, na perspectiva de uma assistência integral, respeitada a vontade do paciente ou de seu representante legal". Desse modo, observou-se com os resultados da presente pesquisa, a problemática de que em geral, os alunos de medicina não têm visto profissionais da área da saúde praticando ortotanásia, sendo estes principalmente da fase de internato da graduação e que apontaram anteriormente saber distinguir corretamente o conceito, ou seja, não estaria associado a não saber o que seria esta ação.

De acordo com Dubón-Peniche e Bustamente-Leija (2020), por ser inevitável que os trabalhadores da área da saúde lidem com a morte, necessitam de uma reflexão crítica apurada para garantir que as opções adequadas sejam ofertadas tanto aos enfermos como para toda sua rede familiar inserida na situação; e isto, envolve a inserção da bioética e atualizações frequentes nas legislações e demais aspectos relacionados. Nesse cenário, percebe-se que é mister intervir ainda na graduação e com foco na formação desse senso crítico, pois, perceptivelmente, os estudantes são bastante influenciados a não aprovar práticas benéficas e aprovar as maléficas devido ao desconhecimento teórico que posteriormente poderia também ser complementado pelos estágios do internato, com um currículo oculto equivocado, orientado por preceptores despreparados e assim conceitos inadequados serão sedimentados. 
Verifica-se uma busca desses estudantes por uma relação médico-paciente mais equilibrada, que envolva mais humanização e menos impessoalidade e isto não deve ocorrer apenas por meio de aulas teóricas, mas através de vivência e algo mais prático, que indique que pior do que morrer, é morrer na solidão, como ocorre nos dias atuais. Contudo, as universidades médicas tem proporcionado a seus alunos uma formação mais técnica e que valoriza mais a tecnologia e a especialização, se comparado à escuta qualificada e à relação médico-paciente (Figueiredo \& Stano, 2013).

No contexto brasileiro atual, a pandemia causada pelo coronavírus amplifica as dificuldades em lidar com o processo de finitude da vida e a solidão consequente a necessidade de contingência da disseminação do virus. Karnal (2020) pontua que pandemias estão inseridas nas tragédias históricas que afetam o presente e, por conseguinte, adaptam uma nova realidade. Dessa maneira, um estudo realizado por Frossard et al. (2020) identificou os termos mais significativos do campo textual do LinkedIn (rede social focada em relações profissionais) entre março a abril de 2020, possibilitando a observação de que "morte solitária" foi o mais citado. A restrição da liberdade causada pela pandemia acarreta agravamento de quadros emocionais (Alvim, 2020) e, de acordo com a Fundação Oswaldo Cruz (2020), ocasiona estado de estresse e alerta com maior frequencia nos individuos. Por este motivo, o aprendizado acerca do saber lidar com a morte e instituição de cuidados paliativos conforme correto julgamento da necessidade para não cometer infrações graves com enfermos que já estão inseridos em uma situação tao delicada fisíca e psicologicamente, se faz tão importante para a boa administração das situações causadas pela internação solitária dos pacientes infectados com o virus da situação pandêmica brasileira atual.

Por fim, as limitações deste estudo estão relacionada com o fato de ter sido realizado em apenas duas faculdades de Medicina, consequentemente, sendo representada por uma quantidade restrita de acadêmicos. Entretanto, suficientes para responder os objetivos propostos.

\section{Considerações Finais}

Os resultados deste estudo levam à reflexão sobre a importância da atuação da coordenação dos cursos de Medicina no sentido de elaborar estratégias eficazes de aprendizagem, pois, o fato de 19\% definirem incorretamente ortotanásia, 7\%, eutanásia e 17\%, distanásia, é indicativo básico de desestruturação da grade curricular, que gera um grande despreparo nas atividades profissionais médicas diárias e aumenta a probabilidade de futuro erro médico, imperícia ou outras atitudes antiéticas e infrações graves.

Existe uma diminuição nos acertos da definição de eutanásia, distanásia e ortotanásia entre estudantes que estão na iminência da formação, demonstrando que não há intervenções direcionadas para aprimoramento do conhecimento da temática ao longo da faculdade e a importância da discussão frequente, desde o primeiro período do curso de Medicina até a atuação profissional para reduzir os danos que possam ser causados tanto pelo despreparo em lidar com a morte, como pela falta de conhecimento sobre eutanásia, distanásia e ortotanásia.

Pode-se dizer ainda que, o fato do estudante concordar/ discordar/ não saber opinar é influenciado pelo saber ou não, como a prática é realizada, principalmente no que se refere à distanásia. É necessário garantir eficácia nos projetos de aprimoramento que mudem estatísticas maléficas, demonstradas por exemplo no fato de que $43 \%$ dos alunos responderam que aprovam a prática da distanásia sem saber corretamente sua definição.

Além disso, pôde-se evidenciar o despreparo enfrentado pelos acadêmicos de medicina em lidar com o processo de finitude, dado a forma superficial e rápida de abordagem da temática durante a formação acadêmica, o que indica também uma necessidade de se expandir o espaço para a informação, discussão e reflexão sobre este processo tão complexo, de forma a oportunizar aos acadêmicos o real compreender da morte e do morrer, implicações estas que se não forem sanadas terão forte influência na formação e atuação destes futuros profissionais, podendo por falta do preparo para tal assistência, desenvolver sentimento de culpa e fracasso e até mesmo ter sua saúde mental e emocional comprometida. 
Ademais, é mister uma reavaliação da grade curricular focada na vivência e na escuta qualificada ao contrário do que ocorre atualmente, em que se valoriza a formação mais técnica e especializada. Salienta-se que as interferências individuais em cada instituição de ensino superior é evidenciada e pautada na necessidade de mais pesquisas sobre a temática abordada neste estudo.

É necessário, portanto, que trabalhos futuros avaliem a percepção dos acadêmicos após um período de trabalho, para que seja possível realizar estudos comparativos de acordo com o tempo de profissão. Há também a possibilidade de aprimorar a acurácia através do detalhamento da percepção sobre a temática dentro de cada especialidade médica. Por fim, detalhar o nível de conhecimento dos médicos no âmbito dos cuidados paliativos também seria de extrema relevância para o desenvolvimento de projetos direcionados a intervir beneficamente na formação médica.

\section{Referências}

Aguiar, J. A. R. D., Oliveira, K. L. D., Martins, M. S. C., Dorne, S. R., Pirissato, F. C., Vitto, D. M., Rocha, E. A. D., Junior, J. M. D. P. P., Rocha, S. S. S., \& Alves, S. S. (2020). A mulher no mercado de trabalho. Monumenta - Revista Científica Multidisciplinar, 1(1), 22-34. https://revistaunibf.emn uvens.com.br/monumenta/article/view/4

Almeida, H. R. A. de, \& Melo, C. de F. (2018). Práticas de ortotanásia e cuidados paliativos em pacientes com câncer terminal: Uma revisão sistemática da literatura. Enfermería Global, 17(3), 529-574. https://doi.org/10.6018/eglobal.17.3.299691

Alvim, F. C. d. S. (2020). Sobre a morte e o morrer - aspectos históricos e o contexto da pandemia covid-19. Única Cadernos Acadêmicos, 3(1). http://co.unicaen.com.br:89/periodicos/index.php/UNICA/article/view/174/151

Aragão, L. H. F. B. (2018). Avaliação da intervenção educativa sobre cuidados paliativos dirigida a estudantes de medicina [Trabalho de conclusão de curso não publicado]. Universidade Tiradentes.

Azeredo, N. S. G., Rocha, C. F., \& Carvalho, P. R. A. (2011). O enfrentamento da morte e do morrer na formação de acadêmicos de Medicina. Revista Brasileira de Educação Médica, 35(1), 37-43. https://doi.org/10.1590/S0100-55022011000100006

Barbieri, N. A., \& Sarti, C. A. (2011). Psicanálise e antropologia: Diálogos possíveis. Revista Latinoamericana de Psicopatologia Fundamental, 14, 57-69. https://doi.org/10.1590/S1415-47142011000100004

Barroso, E. C. R., Rêgo, P. R. B., Oliveira, C. A. de B., Moreira, P. C., Octaviani, J. V., Guerra, L. M., Gondinho, B. V. C., Checchi, M. H. R. D., \& Campelo, V. (2020). Conhecimento De Graduandos Em Medicina Sobre A Morte E O Morrer Na Formação Acadêmica. REVISTA FAIPE, 10(2), 1-11. https://www.revistafaipe.com.br/index.php/RFAIPE/article/view/202

Cano, C. W. de A., Silva, A. L. C. da, Barboza, A. F., Bazzo, B. F., Martins, C. P., Iandoli Júnior, D., Benites, L. da S. B., Terceros, L. B., \& Nantes, R. dos S. G. (2020). Finitude da vida: Compreensão conceitual da eutanásia, distanásia e ortotanásia. Revista Bioética, 28, 376-383. https://doi.org/10.1590/198380422020282399

Cardin, V. S. G., \& Nery, L. M. G. (2021). Até quando prolongar a vida? Revista Brasileira de Sociologia do Direito, 8(1), 18-31. https://doi.org/10.21910/rbsd.v8i1.386

CNN Brasil. (2020). O Mundo Pós-Pandemia com Leandro Karnal-Relações Pessoais Cannot transcribe this video. https://www.youtube.com/w atch?v=pDMAfc1 ya1 M

Constituição da República Federativa do Brasil de 1988. (1988). http://www.planalto.gov.br/ccivil_03/constituicao/constituicao.htm

Correia, D. S., Taveira, M. das G. M. M., Marques, A. M. V. F. A., Chagas, R. R. S., Castro, C. F., \& Cavalcanti, S. L. (2020). Percepção e Vivência da Morte de Estudante de Medicina durante a Graduação. Revista Brasileira de Educação Médica, 44. https://doi.org/10.1590/1981-5271v44.1-20190200

Couceiro, F. B. L., Bonini, L. M. de M., Afférri, C., Imada, H. N., Nictheroy, L. M., \& Silva, R. A. da. (2019). A Percepção Da Morte E Do Morrer Por Estudantes De Medicina. Diálogos Interdisciplinares, 8(10), 1-13. https://revistas.brazcubas.br/index.php/dialogos/article/view/821

Cruz, N. A. O. da, Nóbrega, M. R., Gaudêncio, M. R. B., Andriani, M. T., Farias, T. Z. T. T. de, Pimenta, T. S., Fernandes, A. R. N., \& Pereira, R. C. F. (2021). O papel da equipe multidisciplinar nos cuidados paliativos em idosos. Research, Society and Development, 10(8), e52110817433-e52110817433. https://doi.org/10.33448/rsd-v10i8.17433

Duarte, A. C., Almeida, D. V. de, \& Popim, R. C. (2015). A morte no cotidiano da graduação: Um olhar do aluno de medicina<sup/>. Interface Comunicação, Saúde, Educação, 19, 1207-1219. https://doi.org/10.1590/1807-57622014.1093

Dubón-Peniche, M. del C., \& Bustamante-Leija, L. E. (2020). Entre la enfermedad y la muerte: «Eutanasia». Cirugía y Cirujanos, 88(4), 1719. https://doi.org/10.24875/CIRU.18000626 
Felix, Z. C., Costa, S. F. G. da, Alves, A. M. P. de M., Andrade, C. G. de, Duarte, M. C. S., \& Brito, F. M. de. (2013). Eutanásia, distanásia e ortotanásia: Revisão integrativa da literatura. Ciência \& Saúde Coletiva, 18, 2733-2746. https://doi.org/10.1590/S1413-81232013000900029

Ferreira, J. M. G., Nascimento, J. L., \& Sá, F. C. de. (2018). Profissionais de saúde: Um ponto de vista sobre a morte e a distanásia. Revista Brasileira de Educação Médica, 42, 87-96. https://doi.org/10.1590/1981-52712015v42n3RB20170134

Figueiredo, M. das G. M. C. de A., \& Stano, R. de C. M. T. (2013). O estudo da morte e dos cuidados paliativos: Uma experiência didática no currículo de medicina. Revista Brasileira de Educação Médica, 37(2), 298-306. https://doi.org/10.1590/S0100-55022013000200019

Fiorotti, K. P., Rossoni, R. R., \& Miranda, A. E. (2010). Perfil do estudante de Medicina da Universidade Federal do Espírito Santo, 2007. Revista Brasileira de Educação Médica, 34, 355-362. https://doi.org/10.1590/S0100-55022010000300004

Frossard, A. G. de S., Aguiar, A. B. de, \& Fontes, E. (2020). COVID-19 e cuidados paliativos: uma análise netnográfica. Ambiente: Gestão e Desenvolvimento, 140-152. https://doi.org/10.24979/ambiente.v1i1.808

Leite, S. de S., Áfio, A. C. E., Carvalho, L. V. de, Silva, J. M. da, Almeida, P. C. de, \& Pagliuca, L. M. F. (2018). Construction and validation of an Educational Content Validation Instrument in Health. Revista Brasileira de Enfermagem, 71(suppl 4), 1635-1641. https://doi.org/10.1590/0034-7167-20170648

Lins, C. de F. M., Bezerra, G. A. M., \& Lima, K. G. (2018). Percepção de brasileiros sobre morte digna. Revista Portuguesa de Investigação Comportamental e Social, 4(1), 14-21. https://doi.org/10.31211/rpics.2018.4.1.71

Lira, A. da S., Santos, M. D., Ferreira, A. C., Buchardt, A. T., Gama, I. L., Oliveira, L. C. P. de, \& Kummer, R. (2021). Mulheres no atual mercado de trabalho A importância da igualdade de gênero. Nativa - Revista de Ciências Sociais do Norte de Mato Grosso, 9(1). https://www.re vistanativa.com.br/index.php/nativa/article/view/398

Lysakowski, S., \& Menin, G. E. (2019). Utilização de simulação clínica no ensino sobre terminalidade da vida na Enfermagem: Relato de experiência. Revista Docência do Ensino Superior, 9, 1-14. https://doi.org/10.35699/2237-5864.2019.2559

Martins, L. A., Cunha, J. H. da S., Ferreira, L. A., Frizzo, H. C. F., \& Carvalho, L. B. de C. P. (2019). Significado da morte de pacientes para os profissionais de saúde em unidade de terapia intensiva. Revista Família, Ciclos de Vida e Saúde no Contexto Social, 7(4), 448-457. https://doi.org/10.18554/refacs.v7i4.3671

Moraes, S. A. F. de, \& Kairalla, M. C. (2010). Assessing knowledge of Medical undergraduate students on palliative care in end-stage disease patients. Einstein (São Paulo), 8, 162-167. https://doi.org/10.1590/S1679-45082010AO1464

Morais, I. M. de, Nunes, R., Cavalcanti, T., Soares, A. K. S., \& Gouveia, V. V. (2016). Percepção da "morte digna" por estudantes e médicos. Revista Bioética, 24, 108-117. https://doi.org/10.1590/1983-80422016241112

Muñoz, D. R. (2004). Bioética: A mudança da postura ética. Revista Brasileira de Otorrinolaringologia, 70, 578-579. https://doi.org/10.1590/S003472992004000500001

Neves, T. I. (2020). O universalismo da cura em Freud. Ágora: Estudos em Teoria Psicanalítica, 23(1), 21-29. https://doi.org/10.1590/1809-44142020001003

Orth, L. C., Haragushiku, E. Y., Freitas, I. C. S., Hintz, M. C., Marcon, C. E. M., \& Teixeira, J. F. (2020). Conhecimento do Acadêmico de Medicina sobre Cuidados Paliativos. Revista Brasileira de Educação Médica, 43, 286-295. https://doi.org/10.1590/1981-5271v43suplemento1-20190039

Ricoldi, A., Arlene, A A., \& Amelia. (2016). Mulheres No Ensino Superior Brasileiro: Espaço Garantido E Novos Desafios. Arlene Ricoldi e Amélia Artes. ex аеquo, 1, 149-161.

Santos, C. T. A. dos, Memorian), S. D. S. M. (in, Freitas, K. D. O., \& Vasconcelos, E. V. (2020). Percepção de acadêmicos de enfermagem sobre o processo morte e morrer: Implicações na formação profissional. Enfermagem em Foco, 11(3), Article 3. https://doi.org/10.21675/2357-707X.2020.v11.n3.3243

Santos, L. R. G. dos, Menezes, M. P., \& Gradvohl, S. M. O. (2013). Conhecimento, envolvimento e sentimentos de concluintes dos cursos de medicina, enfermagem e psicologia sobre ortotanásia. Ciência \& Saúde Coletiva, 18, 2645-2651. https://doi.org/10.1590/S1413-81232013000900019

Fundação Oswaldo Cruz. (2020). Saúde-Mental-e-Atenção-Psicossocial-na-Pandemia-Covid-19-recomendações-gerais. Fiocruz Brasília. https://www.fiocruzbrasilia.fiocruz.br/wp-content/uploads/2020/04/Saúde-Mental-e-Atenção-Psicossocial-na-Pandemia-Covid-19-recomendações-gerais.pdf

Scottini, M. A., Siqueira, J. E. de, \& Moritz, R. D. (2018). Direito dos pacientes às diretivas antecipadas de vontade. Revista Bioética, 26, 440-450. https://doi.org/10.1590/1983-80422018263264

Silva, J. A. C. da, Souza, L. E. A. de, Costa, J. L. F., \& Miranda, H. da C. (2015). Conhecimento de estudantes de medicina sobre o testamento vital. Revista Bioética, 23(3), 563-571. https://doi.org/10.1590/1983-80422015233093

Siqueira Perboni, J., Zilli, F., \& Oliveira, S. G. (2018). Profissionais de saúde e o processo de morte e morrer dos pacientes: Uma revisão integrativa. Persona y Bioética, 22(2), 288-302. https://doi.org/10.5294/pebi.2018.22.2.7

SurveyMonkey Audience. (2019). Calculadora de tamanho de amostra. SurveyMonkey. https://pt.surveymonkey.com/mp/sample-size-calculator/

Trevisano, R. G., de Almeida, J. V., \& Barreto, D. C. A. (2019). O Olhar Da Enfermagem No Processo De Luto. Revista Saúde em Foco, 14.

Zurriaráin, R. G. (2019). Cuidados Paliativos: Solución Ética Acorde Con la Dignidad Humana Al Final de la Vida. Persona y Bioética, 23(2), 180-193. https://doi.org/10.5294/pebi.2019.23.2.2 
